\title{
Growth Control of N-Polar GaN in Plasma-Assisted Molecular Beam Epitaxy
}

\author{
A.M. Mizerov*, V.N. JMerik, V.K. Kaibyshev, \\ T.A. Komissarova, S.A. Masalov, A.A. Sitnikova \\ AND S.V. IVANOV
}

Ioffe Physico-Technical Institute

26 Polytekhnicheskaya str., St. Petersburg 194021, Russia

\begin{abstract}
The paper reports on plasma-assisted MBE growth of good quality $\mathrm{N}$-face GaN layers directly on $\mathrm{c}-\mathrm{Al}_{2} \mathrm{O}_{3}$ substrates. Growth kinetics under different growth conditions (substrate temperature, Ga to activated nitrogen flux ratio, etc.) during deposition of $\mathrm{GaN}(0001)$ and $\mathrm{GaN}(000 \overline{1})$ both by the ammonia-based MBE or plasma-assisted MBE was studied. It was found that atomically smooth surface of $1 \mu \mathrm{m}$ thick $\mathrm{GaN}(000 \overline{1})$ films can be achieved by plasma-assisted MBE at the relatively high substrate temperature $T_{\mathrm{S}} \approx 760^{\circ} \mathrm{C}$ and $\mathrm{Ga}$ to activated nitrogen flux ratio $F_{\mathrm{Ga}} / F_{\mathrm{N}^{*}} \approx 1.8$.
\end{abstract}

PACS numbers: 78.55.Cr, 81.05.Ea, 81.15.Hi

\section{Introduction}

Plasma-assisted molecular beam epitaxy (PA MBE) is one of the main growth techniques of group-III nitrides. It allows one to grow the GaN films with either N- or Ga-polarity depending on the type of substrate or buffer layer [1]. The growth of Ga-face GaN has been found to be preferable for most device applications, since it usually promotes a two-dimensional growth mode with the atomically smooth surface. In contrary, most researchers avoid the N-polar GaN layers possessing as a rule the rough surface morphology preventing their device applications. However, there is a great interest in using N-face (0001) films in AlGaN heterostructures for high electron mobility transistors. In this case the internal polarization fields have opposite directions to those in the conventional Ga-polar structures, that can result in different carrier distribution and improve the output

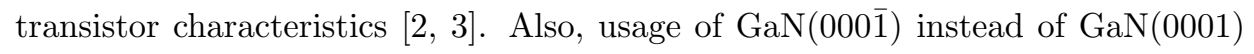

*corresponding author; e-mail: mizerov@beam.ioffe.ru 
as a buffer layer results in smoother morphology and better quality of InN epilayers [4]. Recently, some advantages of N-face InGaN/GaN multi-quantum well structures emitting in green have been reported [5].

The paper reports on the comparative study of growth kinetics of GaN films of different polarity grown by either ammonia-based $\mathrm{MBE}\left(\mathrm{NH}_{3}-\mathrm{MBE}\right)$ or PA MBE on c-sapphire at different substrate temperatures $\left(T_{\mathrm{S}}\right)$, group III $(\mathrm{Ga})$ to active nitrogen flux ratios $\left(F_{\mathrm{Ga}} / F_{\mathrm{N}^{*}}\right)$, etc. The results on optimization of PA MBE growth conditions to improve the surface morphology of $\mathrm{GaN}(000 \overline{1})$ layers and their optical and electrical properties are presented.

\section{Experiment}

The experiments were carried out using the MBE Compact 21T (Riber) setup equipped with both an $\mathrm{NH}_{3}$ injector and a plasma source HD-25 (Oxford Appl. Res.) to realize either $\mathrm{NH}_{3}-\mathrm{MBE}$ or PA MBE, respectively. In the former case, $1 \mu \mathrm{m}$ thick GaN epilayers were grown on the annealed and nitridated c-sapphire substrates at growth rate of $\approx 1 \mu \mathrm{m} / \mathrm{h}$. $130 \mathrm{~nm}$ thick GaN layers grown at low temperature $\left(T_{\mathrm{S}} \approx 500^{\circ} \mathrm{C}\right)$ and annealed afterwards at $T_{\mathrm{S}}=850^{\circ} \mathrm{C}$ for $10 \mathrm{~min}$ were used as nucleation layers [6]. Different $\mathrm{NH}_{3}$-fluxes $(\leq 200 \mathrm{sccm})$, substrate temperatures $\left(T_{\mathrm{S}} \leq 860^{\circ} \mathrm{C}\right.$ ) and $F_{\mathrm{Ga}} / F_{\mathrm{N}^{*}}$ ratios (down to $1 / 30$ ) were employed.

GaN epilayers grown by PA MBE were deposited directly on the annealed $\left(T_{\mathrm{S}} \approx 800^{\circ} \mathrm{C}\right)$ and plasma-nitridated c-sapphire substrates or $3 \mu \mathrm{m}$ thick $\mathrm{GaN}(0001) / \mathrm{c}-\mathrm{Al}_{2} \mathrm{O}_{3}$ templates grown by metal-organic chemical vapor deposition (MOCVD). The rf-power $(Q)$ was varied within the 110-180 $\mathrm{W}$ range at the constant $\mathrm{N}_{2}$ flow rate of $q_{\mathrm{N}_{2}}=5 \mathrm{sccm}$, that allows one to linearly regulate GaN growth rate from 0.2 up to $0.7 \mu \mathrm{m} / \mathrm{h}$, respectively [7]. GaN films were grown at $T_{\mathrm{S}}$ and $F_{\mathrm{Ga}} / F_{\mathrm{N}}$ varied within the ranges of $650-820^{\circ} \mathrm{C}$ and $0.7-1.8$, respectively.

The substrate temperature was measured by an IR-pyrometer. In situ laser interference reflectometry and reflected high energy electron diffraction (RHEED) was used to monitor the growth rate, surface morphology and stoichiometry. GaN surface polarity was identified by the standard technique based on observation of GaN film morphology after its chemical etching in $2 \mathrm{M} \mathrm{NaOH}$ for 10 min at room temperature. GaN surface morphology was studied by using scanning electron (SEM), scanning tunneling (STM), atomic force (AFM) and transmission electron (TEM) microscopes. Optical and electrical properties of the GaN films were characterized by photoluminescence (PL) spectroscopy and the Hall measurements.

\section{Result and discussion}

The GaN stoichiometric growth conditions $\left(F_{\mathrm{Ga}} / F_{\mathrm{N}^{*}} \approx 1\right)$ in the case of $\mathrm{NH}_{3}$-MBE were defined using observation of the transition from $\mathrm{N}$-rich to Ga-rich growth using RHEED at the decrease in the ammonia flux and fixed $F_{\mathrm{Ga}}$ and $T_{\mathrm{S}}$. This transition accomplishes by an abrupt decrease in a GaN growth rate to zero (Fig. 1a) due to formation of Ga blocking layer on the GaN surface [8]. 


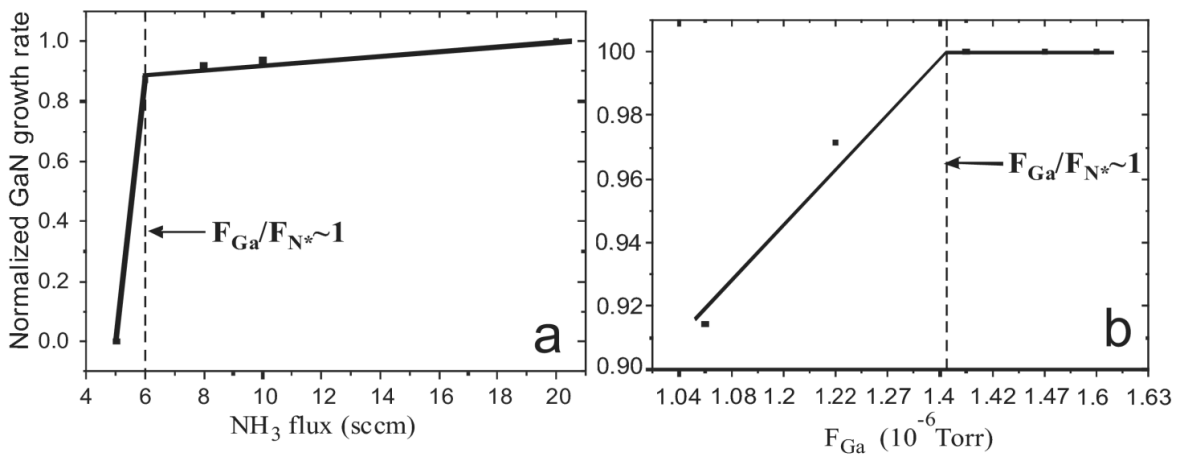

Fig. 1. Determination of stoichiometric conditions during growth of $\mathrm{GaN}$ by (a) $\mathrm{NH}_{3}-$ $-\operatorname{MBE}\left(T_{\mathrm{S}}=800^{\circ} \mathrm{C}\right)$; (b) $\mathrm{PA} \operatorname{MBE}\left(T_{\mathrm{S}}=700^{\circ} \mathrm{C}\right)$.

For PA MBE the analogical transition was observed during gradual rising of $F_{\mathrm{Ga}}$ at the fixed $Q, T_{\mathrm{S}}$ and nitrogen flow rate $q_{\mathrm{N}_{2}}$, and the $F_{\mathrm{Ga}} / F_{\mathrm{N}^{*}} \approx 1$ conditions correspond to the beginning of saturation in the GaN growth rate dependence on $F_{\mathrm{Ga}}$, as shown in Fig. $1 \mathrm{~b}$.

It has been found that different stoichiometric conditions should be kept for two-dimensional (2D) growth of $\mathrm{GaN}$ by $\mathrm{NH}_{3}-\mathrm{MBE}$ and PA MBE. The former must be run at the N-rich conditions with $F_{\mathrm{Ga}} / F_{\mathrm{N}^{*}} \leq 1 / 30\left(q_{\mathrm{NH}_{3}} \geq 200 \mathrm{sccm}\right)$ and rather high $T_{\mathrm{S}}>800^{\circ} \mathrm{C}$. On the contrary, in the later case only slightly Ga-rich conditions with $F_{\mathrm{Ga}} / F_{\mathrm{N}^{*}} \approx 1.1-1.3$ lead to the $2 \mathrm{D}$ growth of the GaN films with atomically smooth surface at $T_{\mathrm{S}}=700^{\circ} \mathrm{C}$, while the higher values of $F_{\mathrm{Ga}} / F_{\mathrm{N}^{*}}$ are required at the elevated $T_{\mathrm{S}}\left(F_{\mathrm{Ga}} / F_{\mathrm{N}} \approx 1.8\right.$ at $\left.T_{\mathrm{S}}=760^{\circ} \mathrm{C}\right)$.

Figure 2 shows different dependences of GaN growth rate versus $T_{\mathrm{S}}$ for both kinds of MBE technology. In the case of $\mathrm{NH}_{3}-\mathrm{MBE}$ the GaN growth rate at the fixed $F_{\mathrm{Ga}}, q_{\mathrm{NH}_{3}}$ giving $F_{\mathrm{Ga}} / F_{\mathrm{N}^{*}} \approx 1 / 30$ begins to drop at $T_{\mathrm{S}}>820^{\circ} \mathrm{C}$ (Fig. 2a) and shows the activation energy of $\approx 4.5 \mathrm{eV}$. This value reflects presumably the enthalpy of GaN decomposition under the N-rich conditions and correlates well with previously reported data $(\approx 4.0 \mathrm{eV})$ on $\mathrm{GaN}$ metal organic vapor phase epitaxy (MOVPE) growth [9]. For PA MBE, the growth rate starts to decrease at lower temperature $T_{\mathrm{S}} \approx 750^{\circ} \mathrm{C}$ (Fig. $2 \mathrm{~b}$ ), as the growth occurs at much higher $F_{\mathrm{Ga}} / F_{\mathrm{N}^{*}}$ ratio. The observed activation energy around $3 \mathrm{eV}$ is close to that of elemental Ga evaporation $(\approx 2.72 \mathrm{eV}$, see e.g. [10]), that implies involving of both solid and liquid phases in Ga desorption from the GaN growth surface.

The chemical etching experiments revealed Ga- and N-polarity of the GaN/c$\mathrm{Al}_{2} \mathrm{O}_{3}$ films grown by $\mathrm{NH}_{3}-\mathrm{MBE}$ and PA MBE, respectively. The films grown on Ga-face GaN-templates had the same (i.e. Ga-) polarity.

Study of the surface morphology revealed that $\mathrm{GaN} / \mathrm{c}-\mathrm{Al}_{2} \mathrm{O}_{3}$ films possess the grain features governed by a type of MBE process used and growth conditions. Figure 3a shows an AFM-image of the GaN film grown by $\mathrm{NH}_{3}-\mathrm{MBE}$ at $T_{\mathrm{S}}=$ $820^{\circ} \mathrm{C}$ and $F_{\mathrm{Ga}} / F_{\mathrm{N}^{*}}=1 / 30$, corresponding to the onset of GaN decomposition 


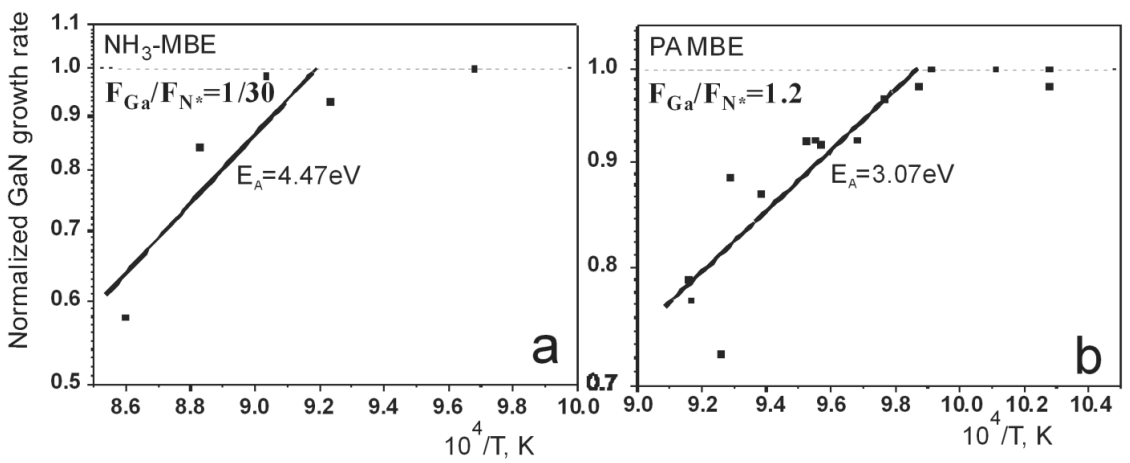

Fig. 2. In situ measurements of $\mathrm{GaN}$ growth rate versus substrate temperature during (a) $\mathrm{NH}_{3}-\mathrm{MBE}$ at fixed $F_{\mathrm{Ga}}, q_{\mathrm{NH}_{3}}$ and $F_{\mathrm{Ga}} / F_{\mathrm{N}^{*}} \approx 1 / 30$; (b) PA MBE at fixed $F_{\mathrm{Ga}}, q_{\mathrm{N}_{2}}$, $Q$ and $F_{\mathrm{Ga}} / F_{\mathrm{N}^{*}} \approx 1.2$.

(Fig. 2a). This layer is characterized by root mean square (rms) roughness of $5 \mathrm{~nm}$ and $0.4 \mathrm{~nm}$ over $3 \times 3 \mu \mathrm{m}$ and $200 \times 200 \mathrm{~nm}$, respectively. The similar grain features were found for $\mathrm{GaN}(000 \overline{1})$ grown by PA MBE. Films grown at the low $T_{\mathrm{S}}=700^{\circ} \mathrm{C}$ show smaller grains with the characteristics lateral size $L \approx 1 \mu \mathrm{m}$ and $\mathrm{rms} \approx 6.5 \mathrm{~nm}$ over $5 \times 5 \mu \mathrm{m}$ (Fig. $3 \mathrm{~b}$ ). At this $T_{\mathrm{S}}$ the parameters of the films might be improved by increasing $F_{\mathrm{Ga}}$ only, but it was accompanied by undesirable formation of Ga microdroplets. To overcome this problem the higher $T_{\mathrm{S}}=760^{\circ} \mathrm{C}$ was used that requires the $F_{\mathrm{Ga}} / F_{\mathrm{N}^{*}}$ ratio to be as high as 1.8 to keep the $2 \mathrm{D}$ growth mode. The $\mathrm{N}$-face $\mathrm{GaN}$ layers grown under the higher $T_{\mathrm{S}}$ demonstrated larger grain size and smoother morphology $(L \approx 1.5 \mu \mathrm{m}$ with rms of $3.4 \mathrm{~nm}$ and $<0.5 \mathrm{~nm}$ over a $5 \times 5 \mu \mathrm{m}$ and $200 \times 200 \mathrm{~nm}$ areas, respectively), comparable with the typical morphology parameters of Ga-face GaN grown by PA MBE or $\mathrm{NH}_{3}$ -MBE (Fig. 3c). Figure 3d demonstrates the STM image of the GaN(0001) layer grown by PA MBE atop of the MOCVD template substrate at $T_{\mathrm{S}}=700^{\circ} \mathrm{C}$ and $F_{\mathrm{Ga}} / F_{\mathrm{N}^{*}} \approx 1.3[7]$. The surface exhibits the spiral growth pattern with smooth morphology having rms of $1.75 \mathrm{~nm}$ over $1 \times 1 \mu \mathrm{m}$ area.

The results indicate that mechanisms of formation of adlayers with high surface mobility are different for the type of MBE process characterized by different growth temperature and stoichiometric conditions. For $\mathrm{NH}_{3}-\mathrm{MBE}$, the N-rich conditions with the benefit of large surface $\mathrm{H}$ coverage increases the Ga diffusion length through the formation of mobile $\mathrm{Ga}-\mathrm{H}$ complexes [11]. In the case of PA MBE, Ga-rich conditions result in the formation of Ga adlayer providing high surface mobility $[12,13]$. The spiral morphology of the GaN(0001) film grown atop of a GaN-MOCVD template reflects spiral growth mechanism initiated by screw-type dislocations [14].

The low temperature (20 K) PL studies of GaN(0001) films revealed only the exciton-related band at $\approx 3.47 \mathrm{eV}$ with a full width at half maximum (FWHM) of 8 and $15 \mathrm{meV}$ for the films grown at $T_{\mathrm{S}}=760$ and $700^{\circ} \mathrm{C}$, respectively. It 

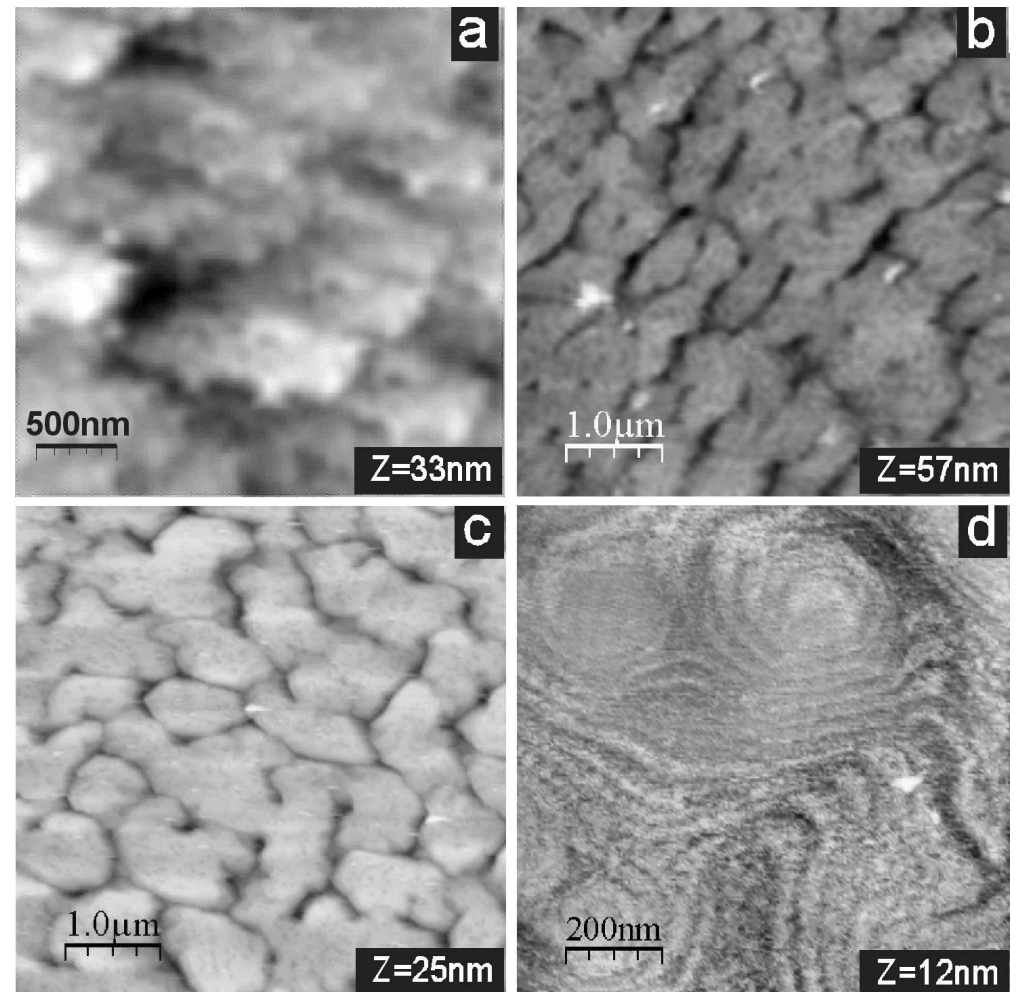

Fig. 3. AFM and STM images of GaN layers grown by (a) $\mathrm{NH}_{3}-\mathrm{MBE}$ on $\mathrm{c}-\mathrm{Al}_{2} \mathrm{O}_{3}$ at $T_{\mathrm{S}}=820^{\circ} \mathrm{C}$; (b) $\mathrm{PA} \mathrm{MBE}$ on $\mathrm{c}-\mathrm{Al}_{2} \mathrm{O}_{3}$ at $T_{\mathrm{S}}=700^{\circ} \mathrm{C}$; (c) PA MBE on $\mathrm{c}-\mathrm{Al}_{2} \mathrm{O}_{3}$ at $T_{\mathrm{S}}=760^{\circ} \mathrm{C}$; (d) PA MBE on $3 \mu \mathrm{m}$ thick MOCVD GaN template at $T_{\mathrm{S}}=700^{\circ} \mathrm{C}$.

should be noticed that these FWHM values are worse in comparison with those for $\mathrm{GaN}(0001)$ layers grown by us on the template at $700^{\circ} \mathrm{C}(\approx 3 \mathrm{meV})[7]$. The Hall measurements of $\mathrm{N}$-face $\mathrm{GaN}$ films grown at $T_{\mathrm{S}}=700^{\circ} \mathrm{C}$ showed the residual electron concentration and mobility values of $n_{\mathrm{e}}=9.4 \times 10^{17} \mathrm{~cm}^{-3}$ and $\mu=$ $200 \mathrm{~cm}^{2} /(\mathrm{V} \mathrm{s})$, respectively. The higher $T_{\mathrm{S}}=760^{\circ} \mathrm{C}$ resulted in reduction of $n_{\mathrm{e}}$ to $2 \times 10^{17} \mathrm{~cm}^{-3}$ at the same mobility, being still one of the order of magnitude higher than that in the best quality Ga-face GaN films [13]. Comparative TEM study of the PA MBE Ga-face GaN films grown on the templates and N-face GaN/ c- $\mathrm{Al}_{2} \mathrm{O}_{3}$ films revealed the density of threading dislocations of $\approx 2 \times 10^{9} \mathrm{~cm}^{-2}$ and $1.5 \times 10^{10} \mathrm{~cm}^{-2}$, respectively. This can explain the wider PL band width and higher residual carriers concentration in the N-face GaN films. Therefore, the development of GaN(0001) PA MBE focusing on the study of initial growth stages is of great importance to decrease in the threading dislocation density. 


\section{Conclusion}

It has been found that atomically smooth surface of $1 \mu \mathrm{m}$ thick $\mathrm{GaN}(000 \overline{1})$ with the typical $\mathrm{rms}$ of $3.4 \mathrm{~nm}$ at $5 \times 5 \mu \mathrm{m}$ and grains dimension of $\approx 1.5 \mu \mathrm{m}$ can be obtained by PA MBE at the relatively high values of $T_{\mathrm{S}} \approx 760^{\circ} \mathrm{C}$ and $F_{\mathrm{Ga}} / F_{\mathrm{N}^{*}} \approx 1.8$. PL spectra of these films are dominated by exciton related peaks with FWHM of $8 \mathrm{meV}$ at $20 \mathrm{~K}$. N-face $\mathrm{GaN} / \mathrm{c}-\mathrm{Al}_{2} \mathrm{O}_{3}$ films show relatively high residual electron concentration $\left(n_{\mathrm{e}}=2 \times 10^{17} \mathrm{~cm}^{-3}\right)$ and low electron mobility $\left(\mu=200 \mathrm{~cm}^{2} /(\mathrm{V} \mathrm{s})\right)$, that can be related to the high threading dislocations density in these films (up to $1.5 \times 10^{10} \mathrm{~cm}^{-2}$ ).

\section{References}

[1] D. Huang, P. Visconti, K.M. Jones, M.A. Reshchikov, F. Yun, A.A. Baski, T. King, H. Morkoç, Appl. Phys. Lett. 78, 26, 4145 (2001).

[2] S. Keller, C.S. Suh, Z. Chen, R. Chu, S. Rajan, N.A. Fichtenbaum, M. Furukawa, S.P. DenBaars, J.S. Speck, U.K. Mishra, J. Appl. Phys. 103, 033708 (2008).

[3] M.N. Wong, S. Rajan, R.M. Chu, T. Palacios, C.S. Suh, L.S. McCarthy, S. Keller, J.S. Speck, U.K. Mushra, Phys. Status Solidi A 204, 2049 (2007).

[4] K. Xu, A. Yoshikawa, Appl. Phys. Lett. 82, 2 (2003).

[5] S. Keller, N.A. Fichtenbaum, M. Furukawa, J.S. Speck, S.P. DenBaas, U.K. Mishra, Appl. Phys. Lett. 90, 191908 (2007).

[6] N. Grandjean, M. Leroux, M. Laügt, J. Massies, Appl. Phys. Lett. 71, 240 (1997).

[7] V.N. Jmerik, A.M. Mizerov, T.V. Shubina, S.B. Listoshin, S.V. Ivanov, Tec. Phys. Lett. 33, 36 (2007).

[8] D. Crawford, R. Held, A.M. Johnston, A.M. Dabiran, P.I. Cohen, MRS Internet J. Nitride Semicond. Res. 1, 12 (1996).

[9] O. Ambacher, M.S. Brandt, R. Dimitrov, T. Metzger, M. Stutzmann, R.A. Fisher, A. Miehr, A. Bergmaier, G. Dollinger, J. Vac. Sci. Technol. B 14, 3532 (1996).

[10] S.V. Ivanov, P.S. Kop'ev, N.N. Ledentsov, J. Cryst. Growth 104, 345 (1990).

[11] D.D. Koleske, A.E. Wickenden, R.L. Henry, J.C. Culbertson, M.E. Twigg, J. Crystal Growth 223, 466 (2001).

[12] C. Adelman, J. Brault, D. Jalabert, P. Gentile, H. Mariette, Guido Mula, B. Daudin, J. Appl. Phys. 91, 12 (2002).

[13] E. Monroy, E. Sarigiannidou, F. Fossard, N. Gogneau, E. Bellet-Amalric, J.-L. Rouvière, S. Monnoye, H. Mank, B. Daudin, Appl. Phys. Lett. 84, 18, 3684 (2004).

[14] S. Vezian, F. Natali, F. Semond, J. Massies, Phys. Rev. B 69, 125329 (2004). 